\title{
Intelligent Information Management is Ready for AI, Blockchain
}

\section{A panel discussion at AllM 2018 looked at how Al, cloud and block- chain will disrupt the intelligent information management space.}

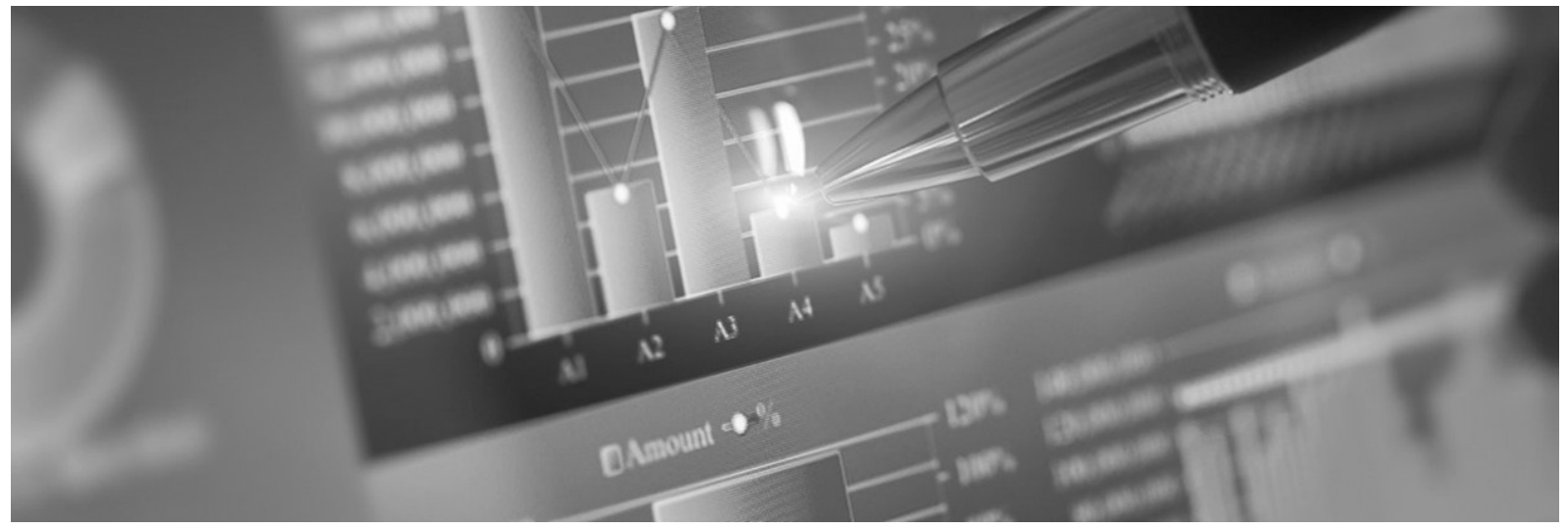

\section{Jesse Scardina}

News Writer, Business Applications 13 Apr 2018

The influx of new technologies can have subtle changes on industries, or it can have massive implications. When it comes to $\mathrm{Al}$, machine learning and the effect on content and information management, it falls in the latter camp.

This is why, on the eve of its 75th anniversary, the Association of Information and Image Management dropped image from its name, adopting the modern moniker of Association of Intelligent Information Management.

"It's pretty handy the acronym still works," said Peggy Winton, president of AlIM, based in Silver Spring, Md. Winton spoke at AlIM Conference 2018, with roughly 800 professionals in attendance. After the opening keynote on Wednesday afternoon, some of the conference's first sessions were dedicated to these new technologies and how they are drastically changing the content management industry.

"The question isn't about where are we going as an industry; it's about where are we at," said Alan Pelz-Sharpe, founder and principal analyst at Deep Analysis, based in Boston.

Pelz-Sharpe acted as the moderator for a session on moving from legacy enterprise content management
(ECM) tools to modern intelligent information management and how Al, cloud and blockchain all play a role.

Shift in Nindset Regarding the Cloud

Initially, there was widespread hesitation for moving to the cloud in the intelligent information management space. However, attitudes changed as other businesses began adopting the cloud and security concerns weren't as apparent.

"Five years ago, the cloud would have been a no-go," said Andrea Chiappe, strategic consultant at Broadridge Financial Solutions, based in Lake Success, N.Y., who was on the panel.

Kashyap Kompella, CEO and principal analyst for rpa2ai, an automation and Al consultancy in Bangalore, India, added that, "initially, the cloud wasn't as secure -- and we've seen that change over the years. There's been a shift in mindset, but there was truth to the notion of the ECM industry being cloud-reluctant."

As use cases grew and more vendors developed products built for the complexities of ECM and intelligent information management, cloud adoption in the content management space grew. And now, sectors that were concerned are becoming enthusiasts.

"We're seeing some financial services becoming early adopters of the cloud," Chiappe said as an example.

What to do About Blockchain 
While the cloud has solidified itself as a necessary technology with a plethora of use cases, the other end of that spectrum is blockchain. The promise and potential of blockchain is apparent, but for those in the intelligent information management space, it may be a couple of years before it starts to find its place.

"To use blockchain to solve an information management problem, we need to understand how things are evolving," said panelist Dan Abdul, vice president of data strategy and commercial implementation for UnitedHealth Group, based in Minneapolis.

Pelz-Sharpe agreed, adding that he is bullish about blockchain for intelligent information management purposes, but sees serious rollouts three to five years down the line.

"The question is, should you be getting up to speed on blockchain now?" Pelz-Sharpe asked the audience.

The panel wasn't all in agreement on the dawning of blockchain.

"If you have the capacity to run a lot of different initiatives, then try blockchain. But it takes a lot of focus and initiative," Kompella said. "What is the opportunity cost of doing a blockchain implementation right now?"

Al is a Nystical Term'

Splitting the gap between technology that is already here -- cloud -- and one that's on the horizon in blockchain, Al is growing in use cases and implementation, but not without some hesitation and concern from those in the intelligent information management space.

"Al is a mystical term," said Carl Hillier, product group head of data capture at Abbyy, based in Milpitas, Calif. Hillier was speaking at a separate workshop session at AllM 2018 focused on determining whether Al is right for an organization. "When the cloud came out, people had a similar feeling."

But as use cases grew and companies could see the benefit, Al adoption continued to grow and intrigue more technological decision-makers.

"We want Al in every aspect of business operations," Abdul said. "Look at the state of U.S. healthcare. There aren't enough humans I could hire to help mitigate all the problems, but Al can help with that. But it's always important to keep an eye on what's coming out -- there's going to be a lot of things that are just noise."

But more so than other technologies, a company needs to have a strategy in place for what they want to solve when implementing Al.

"You don't make your company successful by buying a bucket of Al," Hillier said. "It's not about waving an Al wand -- there's no intrinsic value by itself. It's about picking the right thing to do with $\mathrm{Al}$."

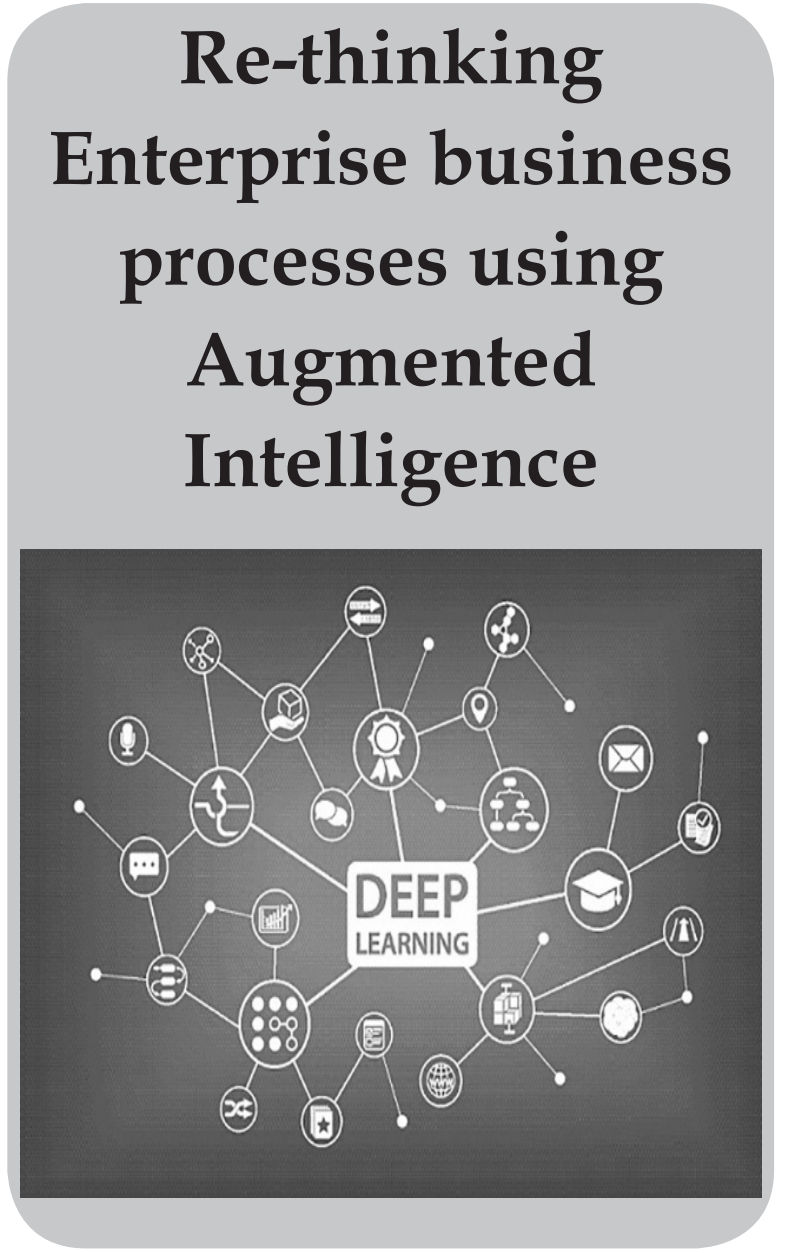

In the 1990s, there was a popular book called Reengineering the Corporation. Looking back now, Reengineering certainly has had a mixed success - but it did have an impact over the last two decades. ERP deployments led by SAP and others were a direct result of the Business Process re-engineering phenomenon.

So, now, with the rise of Al: Could we think of a new form of Re-engineering the Corporation - using Artificial Intelligence? The current group of Robotic process automation companies focus on the UI layer. We could extend this far deeper into the Enterprise. Leaving aside the discussion of the impact of Al on jobs, this could lead to augmented intelligence at the process level for employees (and hence an opportunity for people to transition their careers in the age of $\mathrm{Al}$ ).

Here are some initial thoughts. I am exploring these ideas in more detail. This work is also a part of an Al lab we are launching in London and Berlin in partnership with UPM and Nvidia both for Enterprises and Cities

$44=$\begin{tabular}{ll}
\hline Esisact & Compunet 21 (June - 2018)
\end{tabular} 